\title{
Genomic analysis of Newcastle disease virus strain NA-1 isolated from geese in China
}

\author{
M. Xu $\cdot$ S. Chang $\cdot$ Z. Ding $\cdot$ H.-W. Gao $\cdot$ J.-Y. Wan $\cdot$ \\ W.-S. Liu $\cdot$ L.-N. Liu $\cdot$ Y. Gao $\cdot$ J. Xu
}

Published online: 2 August 2008

(C) Springer-Verlag 2008

\section{Erratum to: Arch Virol (2008) 153:1281-1289 \\ DOI 10.1007/s00705-008-0115-9}

In the published article, the author affiliations are not correct. The corresponding author should be Zhuang Ding (e-mail: Ding_Zhuang@yahoo.com.cn), not Ming Xu.

All the contributions of this research belong to Prof. Zhuang Ding and the Laboratory of Important Pathogen and Loemia of Animals, College of Animal and Veterinary Science, Jilin University, Changchun 130062, People's Republic of China.

The online version of the original article can be found under doi:10.1007/s00705-008-0115-9.

M. Xu $\cdot$ S. Chang $\cdot$ Z. Ding $(\bowtie) \cdot$ Y. Gao

Laboratory of Important Pathogen and Loemia of Animal,

College of Animal and Veterinary Science, Jilin University,

Changchun 130062, People's Republic of China

e-mail: Ding_Zhuang@yahoo.com.cn

M. Xu - H.-W. Gao - J.-Y. Wan - W.-S. Liu - L.-N. Liu

Y. Gao $\cdot$ J. Xu

Military Institute of Veterinary Sciences, Academy of Military

Medical Sciences, Changchun, People's Republic of China

e-mail: amingjlu@163.com 